\title{
PROFILING HEALTH AND SAFETY RISK ASSOCIATED WITH CONSTRUCTION PROJECTS AT THE PRE-CONSTRUCTION STAGE
}

\author{
Patrick Manu
}

\author{
University of the West of England, United Kingdom
}

\section{Summary}

At the pre-construction stage of construction projects it is important for project participants to have an understanding of the health and safety $(H \& S)$ risk profile of a project so that appropriate mitigation measures can be introduced prior to the construction phase where accidents occur. However, at the pre-construction stage there is often very limited information to guide project participants in ascertaining the level of risk associated with a project. Nevertheless, pre-construction decisions such as the features of projects, due to their underlying accident causal influence, can be informative in profiling the H\&S risk associated with a project. Using responses from a survey of UK construction professionals as inputs for a semi-quantitative risk assessment technique, this chapter presents an assessment of the degree of $H \& S$ risk associated with construction project features $(C P F s)$ and the subsequent development of a simple tool (nicknamed, "CRiMT") for profiling the H\&S risk of construction projects. The main highlight of the chapter is that: the CPFs examined are generally associated with medium risk or high risk implying a medium likelihood or a high likelihood of occurrence of accident/harm where such features apply on projects. CRiMT provides a simple and sound means by which project participants (e.g. clients and their design and project management teams) can ascertain the H\&S risk associated with a project at pre-construction, and to also consider relevant risk controls. 


\section{Introduction}

The construction industry is widely noted to be a dangerous industry in respect of the health and safety (H\&S) of workers (ILO, 2005). Despite years of gradual improvements in construction $H \& S$ in some countries, the industry continues to record numerous deaths, injuries, and ill-health of workers in many countries (see Department of Occupational Health and Safety, 2015; HSE, 2015a; Ministry of Manpower, 2015). As a result, efforts continue to be made to further enhance the H\&S situation of the industry. Among the efforts is the emphasis on the early planning of $\mathrm{H} \& \mathrm{~S}$ in project procurement. For instance in the UK, there is the Construction Design and Management (CDM) Regulations 2015 which seek to integrate H\&S into construction project delivery right from the early design stage (HSE, 2015b) by placing legal duties on key project participants including clients and designers. Similar regulations also exist in countries such as Singapore and Australia (e.g. the Workplace Safety and Health (Design for Safety) Regulations 2015 of Singapore, and the Work Health and Safety Acts and Regulations of several Jurisdictions in Australia). Central to the early planning of $H \& S$ is the need for project participants to pay attention to underlying causes of accidents which emanate from the pre-construction phase of project delivery.

Construction project features (CPFs), which are organisational, physical and operational attributes of construction projects are among underlying accident causal factors and they include: nature of project, method of construction, project duration, level of construction, subcontracting, design complexity, site restriction and procurement system (see Mayhew and Quinlan, 1997; Egbu, 1999; Horbury and Hope, 1999; Brabazon et al., 2000; McKay et al., 2002; Strategic Forum for Construction, 2002; Wright et al., 2003; Perttula et al., 2003; Hide et al., 2003; Anumba et al., 2004; Chua and Goh, 2005; Anumba et al., 2006; Ankrah, 2007; Hughes and Ferrett, 2008; Brace et al., 2009; HSE, 2009; Manu et al., 2013). These features largely emanate from pre-construction decisions by client, designers and project managers/planners.

At the pre-construction stage of construction projects it is important for project participants to have an understanding of the $H \& S$ risk associated with a project so that appropriate mitigation measures can be introduced prior to construction. This understanding is also important in order for clients and/or their representatives to be able to appoint project team members (e.g. contractors) who have the competence to manage the H\&S risk in a project. In the UK for example, the Construction Design and Management (CDM) Regulations 2015 recommends that $H \& S$ risk measures ought to be proportionate to the risks in a project (HSE, 2015b). CDM 2015 also requires project participants to have the knowledge, skills and experience (if individuals) and the organisational capability (if an organisation) to manage the H\&S risks in a project (HSE, 2015b). CPFs, being underlying accidents causal factors and the result of pre-construction decisions, can be informative in profiling the H\&S risk associated with a project at the preconstruction stage. This chapter presents a pathway for ascertaining the H\&S risk profile of a project through an evaluation of the $H \& S$ risk associated with the features of projects. In the sections that follow, a review of approaches for assessing H\&S risk is considered in order to determine an appropriate approach for evaluating the $\mathrm{H} \& \mathrm{~S}$ risk associated with CPFs. This is followed by the evaluation of the H\&S risk associated with CPFs and the development of a simple pre-construction phase project H\&S risk profiling tool (nicknamed, “CRiMT”).

\section{H\&S Risk Evaluation}

In terms of $H \& S$, several definitions have been used for risk. Some of these definitions include: "The combination of the likelihood of an occurrence of a hazardous event or exposure(s) and the severity of injury or ill health that can be caused by the event or exposure(s)" (British Standard Institute (BSI), 2008); and "The likelihood of a substance, activity or process to cause harm" 
(Hughes and Ferrett, 2008). According to HSE (2001; 2006), risk is the likelihood that harm will occur. By conceiving H\&S risk associated with a CPF as the likelihood of that CPF to cause harm (e.g. injury or illness), the definitions by HSE $(2001 ; 2006)$ and Hughes and Ferrett (2008) can be instructive in understanding the H\&S risk associated with CPFs. It has been noted that risk is often interchanged with the term, "hazard", although these two are different (HSE, 2001). Hazard is the intrinsic potential of something to cause harm (HSE, 2001), and the HSE (2001) further relates hazard to risk, in this manner: "risk is the chance that someone or something that is valued will be adversely affected in a stipulated way by a hazard". Focusing on the H\&S of people, and in relation to hazard, risk is thus the likelihood that someone will be harmed (i.e. adversely affected) by a hazard (i.e. the potential of something to cause harm).

The methods for evaluating H\&S risk have mainly been categorised as qualitative and quantitative risk evaluation (see BSI, 2008; Pinto et al., 2011). Popular among the qualitative methods is the checklist/questionnaire method (see Pinto et al., 2011). The quantitative methods include failure modes and effects analysis and hazard and operability studies (see BSI, 2008). There are also semi-quantitative or qualitative-quantitative methods which quantify qualitative risk information or use qualitative risk information with corresponding numeric scores (see Aven, 2008; Sachs and Tiong, 2009; WHO and FAO, 2009). A popular method of semiquantitative risk evaluation is risk combination matrix (cf. Risk \& Policy Analyst Ltd., 1999; WHO and FAO, 2009) which some authors prefer to classify as a quantitative method (e.g Hughes and Ferrett, 2008).

Literature provides examples of application of the different types of H\&S risk evaluation methods. For instance, Kariuki and Löwe (2007) developed a qualitative risk evaluation method that systematically identifies human error in process design and the human factors that influence its production and propagation. The New York State Division of Industrial Safety Services used a quantitative method that correlates the degree of risk of various construction activities and the workmen's compensation insurance rates (Knab, 1978). The technique adopted by the New York State Division of Industrial Safety Services was modified by Knab (1978) who developed a model that determines a risk score for various workmen's compensation classifications. Sack et al. (2009) developed the construction hazard assessment with spatial and temporal exposure (CHASTE) method which estimates numerically, safety risk level based on: the probabilities of exposure in space and time; an estimate of the probability of a loss-of-control event occurring per worker in crew; the expected severity of the result of potential accident; and the numbers of workers in a crew. In terms of semi-quantitative risk evaluation, Croner (in Risk \& Policy Analyst Ltd. (1999)) presented a task-based method for rating risk using a risk matrix which combines scores for severity and likelihood of hazard. The product (i.e. multiplication) of these scores provides a risk rating from 1 (very unlikely delay) to 100 (certain/imminent multiple death). The matrix classifies risk as trivial, adequately controlled, and not adequately controlled, on the basis of the need for further action. Hughes and Ferrett (2008) also presented a risk matrix which estimates risk by combining severity of harm (measured by a 3-point scale: slight (1), serious (2), and major (3)) and likelihood of harm (measured by a 3-point scale: low (1), medium (2), and high (3)). The various combinations are assigned a degree of risk ranging from Low (for combination 1-2), medium risk (for combination 3-4) and high risk (for combinations $6-9$ ). Jannadi and Almishari (2003) also developed a risk assessor model which determines a risk score for an activity and a justification factor for a proposed remedy. The risk score is estimated based on severity, exposure, and probability which are all determined using qualitative scales (e.g. minor cuts, for severity; occasionally, for frequency of exposure; and likely, for probability), and are tied to quantitative scores or ratings. 
The above demonstrates the variety of risk evaluation methods applied in H\&S. As noted by several authors (e.g. Smith et al., 2006; Pinto et al., 2011), generally the various methods are valid depending on the context of application. However, these methods have their strengths and weaknesses which should be taken into account when selecting a risk evaluation method.

Although qualitative risk evaluation is easy to use, it is subjective and thus makes it difficult for a third party to understand the basis or rational for the evaluation (WHO and FAO, 2009). Also, qualitative risk evaluation mainly prioritises identified hazards for further analysis and as such does not necessarily give an indication of the likelihood of occurrence of harm (i.e. risk) (WHO and FAO, 2009). A qualitative risk evaluation will thus not be suitable for evaluating the H\&S risk associated with CPFs. With quantitative risk evaluation, the major challenge is the availability or completeness of any historical and numerical data needed for the evaluation (BSI, 2008; Sachs and Tiong, 2009). Previous construction accident causation studies in UK and elsewhere have generally noted the limitations of accident records especially when it comes to studying root accident causal factors which are upstream of the project procurement process (see Suraji, 2001; Bomel Limited et al., 2006; Cooke and Lingard, 2011). Given that CPFs fall in this category of accident causal factors, a purely quantitative risk evaluation will also not be a suitable option.

Semi-quantitative risk evaluation provides an intermediary level between qualitative risk evaluation and quantitative risk evaluation. It offers a more consistent and rigorous approach to evaluating and comparing risks than does qualitative risk assessment, and avoids some of the greater ambiguities that a qualitative risk assessment may produce (WHO and FAO, 2009). It does not require the same mathematical skills as quantitative risk evaluation, nor does it require the same amount of data, which means it can be applied to risks where precise data are missing or unavailable. Semi-quantitative risk evaluation thus appears to be a more suitable approach for assessing the H\&S risk associated with CPFs. Semi-quantitative risk evaluation is however not without any weakness. The resulting risk scores are placed into usually quite broad sets of categories (e.g. risk score 0-3= Low risk, risk score 4-7 = Medium risk, and risk score 8-10= High risk). This weakness can however be overcome if the categories are carefully constructed/defined (WHO and FAO, 2009). As with purely quantitative risk evaluation, a key aspect of semi-quantitative risk evaluation is the risk expression based on which risk is evaluated. The risk expression indicates the risk determining variables and again several risk expressions exist in the H\&S literature. Among the common ones are:

- $\quad$ Risk = likelihood x severity (Risk \& Policy Analyst Ltd., 1999; Hughes and Ferrett, 2008).

- Risk = probability $\mathrm{x}$ severity $\mathrm{x}$ exposure (Jannadi and Almishari, 2003).

- Risk = probability $x$ severity $x$ frequency (Risk \& Policy Analyst Ltd., 1999).

Another common and hence widely used expression is, Risk $=$ Hazard $x$ Exposure (Chicken and Posner, 1998; Duffus and Worth, 2001; Canadian Centre for Occupational Health and Safety, 2008). By this expression, risk (i.e. the likelihood of occurrence of harm) is a function of hazard (i.e. the potential of a thing to cause harm) and exposure to the hazard. This expression is supported by the argument that unless there is hazard, there cannot be risk (HSE, 2000). The role of hazard in determining risk is emphasised by this: "risk is the chance that someone or something that is valued will be adversely affected in a stipulated way by a hazard" (HSE, 2001). The expression also shows that hazard alone does not determine risk but does so through exposure of people to the hazard. Duffus and Worth (2001) support this with the argument that unless there is exposure to a hazard there will be no risk regardless of the degree of the hazard. Hazard, being the potential of a thing to cause harm, coupled with exposure thus determines risk. 
Considering the accident causal influence of CPFs, their potential to influence accident occurrence can be taken as their potential to cause harm to people, as accidents eventually result in harm (e.g. injury and ill-health). The H\&S risk associated with CPFs (i.e. the likelihood of occurrence of accident/harm) can thus be considered in terms of the expression, Risk = hazard $x$ exposure, where hazard (i.e. the potential to cause harm) is taken as the potential of CPFs to influence accident occurrence. Exposure is the extent to which people or objects are subjected to a hazard (Canadian Centre for Occupational Health and Safety, 2008) and can be assessed in various forms such as duration, frequency, concentration, inhalation and contact (see Duffus and Worth, 2001; Canadian Centre for Occupational Health and Safety, 2008). Referring to semiquantitative risk evaluation as a viable approach for evaluating the H\&S risk associated with $\mathrm{CPFs}$, a risk matrix can be used given its wide use and also considering that the mathematical risk expression, Risk = hazard $x$ exposure , can easily be applied in a two-dimensional matrix format when adapted for the context of the H\&S risk associated with CPFs. In terms of the H\&S risk associated with $\mathrm{CPFs}$, the above expression can thus be re-written as:

$H \& S$ risk associated with a $C P F=$ The potential of the CPF to influence accident occurrence $\boldsymbol{x}$ Exposure of workforce.

In order to evaluate the $\mathrm{H} \& \mathrm{~S}$ risk associated with CPFs, the next section presents how the inputs of the expression were determined and subsequently applied.

\section{Research Methods}

The methods/steps applied are given in the following sections.

\section{Determining the potential of CPFs to influence accident occurrence}

To enable measurement of the potential of CPFs (i.e. nature of project, method of construction, project duration, level of construction, subcontracting, design complexity, site restriction and procurement system) to influence accident occurrence, a quantitative approach, in particular survey, was adopted. Contractor personnel including site managers, construction managers, H\&S managers and project managers commonly work on construction project sites in management roles and from their extensive industrial experience in construction are likely to be aware of the above CPFs as well as their impact on H\&S on projects. These professionals were therefore targeted in a survey in order to enable a generic assessment of the CPFs' potential to influence accident occurrence. The reported difficulty in studying underlying causes of accidents using accidents records/cases (see Suraji et al., 2001; Bomel Limited et al., 2006; Cooke and Lingard, 2011) also supported the use of an alternate research approach, in this case a survey, to determine the potential of the CPFs to influence accident occurrence.

A questionnaire was designed to measure the degree of potential of the CPFs to influence accident occurrence using a Likert-type 5-point scale $(0=$ None, $1=$ Low, $2=$ Moderate, $3=$ High, 4 = Very High) similar to that used in a previous accident causation study (see (Hide, 2003)). In order to reach the above groups of contractor personnel, a survey was thus conducted on a sample of contractors randomly drawn from the UK Kompass online directory. A total of 1000 questionnaires were administered to contractors requesting for the participation of a professional in construction management role. The survey yielded 184 valid responses giving a response rate of $18.4 \%$. The respondents' roles are: project manager $(7.61 \%)$, construction manager $(15.76 \%)$, site manager $(2.17 \%)$, H\&S manager $(56.52 \%)$, and other construction roles 
(e.g. managing director, construction director, operations managers and Integrated Manager (Health, safety, environment, and quality)) (17.94\%). Altogether, the professionals have an average of 16.30 years of experience in their roles, an average of 24.31 years of experience in construction and approximately 80 percent have over 10 years of experience in construction. Approximately $70 \%$ of the respondents are members of at least 1 industrial professional body (e.g. Institution of Civil Engineers, Institution of Occupational Health and Safety, Chartered Institute of Building, International Institution of Risk and Safety Management, Institution of Engineers-Ireland, The Institution of Royal Engineers, and the Royal Institute of Chartered Surveyors). The survey results presented in Table 1 show the minimum, maximum, mean score and standard deviation regarding the potential of the CPFs to influence accident occurrence. The table also shows single item inter-rater agreement indices $\left(r_{\mathrm{wg}}\right)$ which show evidence of consensus amongst the respondents (James et al., 1984).

Table 1: Potential of CPFs to influence accident occurrence

\begin{tabular}{|c|c|c|c|c|c|}
\hline $\begin{array}{c}\text { Construction Project } \\
\text { Features }\end{array}$ & $\begin{array}{l}\text { *Mean Potential to } \\
\text { influence accident } \\
\text { occurrence }\end{array}$ & Std. Deviation & Minimum & Maximum & $* * \mathbf{r} W G$ \\
\hline Demolition & 3.1739 & .95367 & 0.00 & 4.00 & 0.55 \\
\hline Underground construction & 2.8368 & .89677 & 0.00 & 4.00 & 0.60 \\
\hline Tight project duration & 2.8361 & .70531 & 0.00 & 4.00 & 0.75 \\
\hline High-level construction & 2.7554 & .89319 & 0.00 & 4.00 & 0.60 \\
\hline Multi-layer subcontracting & 2.6998 & .78400 & 0.00 & 4.00 & 0.69 \\
\hline Complex design & 2.6141 & .84802 & 0.00 & 4.00 & 0.64 \\
\hline Restricted site & 2.6089 & .80872 & 0.00 & 4.00 & 0.67 \\
\hline Restricted site locality & 2.5703 & .76306 & 0.00 & 4.00 & 0.71 \\
\hline Refurbishment & 2.5169 & .92349 & 0.00 & 4.00 & 0.57 \\
\hline $\begin{array}{l}\text { Traditional on-site } \\
\text { construction }\end{array}$ & 2.2174 & .65830 & 0.00 & 4.00 & 0.78 \\
\hline New work & 1.9858 & .75112 & 0.00 & 4.00 & 0.72 \\
\hline Management contracting & 1.9499 & .76143 & 0.00 & 4.00 & 0.71 \\
\hline $\begin{array}{l}\text { Design and build } \\
\text { procurement }\end{array}$ & 1.8260 & .77698 & 0.00 & 4.00 & 0.70 \\
\hline $\begin{array}{l}\text { Traditional method of } \\
\text { procurement }\end{array}$ & 1.8058 & .81008 & 0.00 & 4.00 & 0.67 \\
\hline Unrestricted site locality & 1.7955 & .74548 & 0.00 & 4.00 & 0.72 \\
\hline Unrestricted site & 1.7949 & .78860 & 0.00 & 4.00 & 0.69 \\
\hline Partnering procurement & 1.7709 & .76016 & 0.00 & 4.00 & 0.71 \\
\hline Low-level construction & 1.7111 & .73799 & 0.00 & 4.00 & 0.73 \\
\hline Adequate project duration & 1.6558 & .72922 & 0.00 & 4.00 & 0.60 \\
\hline Single-layer subcontracting & 1.6252 & .72704 & 0.00 & 4.00 & 0.74 \\
\hline Simple design & 1.5475 & .73703 & 0.00 & 3.00 & 0.73 \\
\hline Pre-assembly construction & 1.5146 & .77634 & 0.00 & 4.00 & 0.70 \\
\hline \multicolumn{6}{|c|}{$\begin{array}{l}* \text { Mean ratings are based on a } 5 \text { point scale }(0=\text { none, } 1=\text { low, } 2=\text { moderate, } 3=\text { high, } 4=\text { very high). } \\
*^{*} \mathrm{r}_{\mathrm{WG}}=\text { Single-item inter-rater agreement index. } \mathrm{r}_{\mathrm{WG}} \text { indices are based on a uniform null distribution. Based on } 10,000 \text { simulation runs, } \\
\mathrm{r}_{\mathrm{WG}} \text { values of } 0.08,0.10 \text { and } 0.14 \text { are the } 90 \%, 95 \% \& 99 \% \text { confidence interval estimates respectively for group size of } 184 \text { and } 5 \\
\text { response options (i.e. } 5 \text { point scale). Hence } \mathrm{r}_{\mathrm{WG}} \text { values }>0.14 \text { are evidence of significant agreement at } p<0.01 \text {. }\end{array}$} \\
\hline
\end{tabular}




\section{Determining exposure of workforce to CPF}

It has been argued in Manu et al. (2012) that in the context of CPFs, due to their remoteness in the process of accident causation, workforce exposure to their potential to influence accident occurrence can realistically be assessed at a generic project level such as in the form of the duration within which a CPF applies on a project or by broadly assessing exposure in terms of whether or not a CPF applies to a project. However, given the difficulty in assessing exposure in terms of duration for some CPFs (e.g. level of construction and subcontracting), assessing exposure in terms of whether or not a CPF applies to a project is a more pragmatic option. This means that, if a CPF applies to a project the workforce will be exposed to its potential to influence accident occurrence and where a particular CPF does not apply to a project, the workforce will not be exposed to its potential to influence accident occurrence. In line with semi-quantitative risk evaluation where qualitative information are assigned numeric scales, assessing exposure in this manner can be expressed as a binary situation, where 'zero' is assigned a no exposure condition and 'one' is assigned a condition where the workforce is exposed. It is logical to assign 'zero' to a no exposure situation because without exposure there can be no risk (Duffus and Worth, 2001; HSE, 2001) and as such any degree of potential to influence accident occurrence combined (i.e. multiplied) with a no exposure condition will yield no risk.

\section{Definition of risk categories in risk combination matrix}

Degree of potential of CPFs to influence accident occurrence has been assessed using a 5-point scale $(0=$ None, $1=$ Low, $2=$ Moderate, $3=$ High, and $4=$ Very High $)$. Having determined a semi-quantitative scale for expressing exposure, (i.e. $0=$ workforce not exposed - where a CPF does not apply to a project; and $1=$ workforce exposed - where a CPF applies to a project), the risk expression (i.e. Eqn. 1) was then applied using a risk combination matrix as given in Table 2 below.

Table 2: Risk combination matrix

\begin{tabular}{|l|c|c|c|}
\cline { 3 - 4 } \multicolumn{1}{c|}{} & \multicolumn{3}{c|}{ Exposure } \\
\cline { 3 - 4 } \multicolumn{1}{c|}{} & 0 & 0 & 1 \\
\hline \multirow{3}{*}{$\begin{array}{l}\text { Potential to influence } \\
\text { accident occurrence }\end{array}$} & 1 & $\mathbf{0}$ & $\mathbf{0}$ \\
\cline { 2 - 4 } & 2 & $\mathbf{0}$ & $\mathbf{1}$ \\
\cline { 2 - 4 } & 3 & $\mathbf{0}$ & $\mathbf{2}$ \\
\cline { 2 - 4 } & 4 & $\mathbf{0}$ & $\mathbf{3}$ \\
\hline
\end{tabular}

From the above matrix, the $\mathrm{H} \& \mathrm{~S}$ risk associated with a CPF can range from a score of 0 (being the least) to 4 (being the highest). These numeric levels of risk need to be assigned qualitative risk categories to enable interpretation of the risk matrix. In doing so, the risk categorisation proposed by the BSI (2008) was very instructive. The BSI (2008) proposes a five band risk categorisation and acceptability as follows:

- Very Low: Risk is considered acceptable. No further action is necessary other than to ensure that the controls are maintained.

- Low: No additional controls are required unless they can be implemented at very low cost (in terms of time, money and effort). Actions to further reduce these risks are assigned low priority. 
- Medium: Consideration should be given as to whether the risks can be lowered, but the costs of additional risk reduction measures should be taken into account.

- High: Substantial efforts should be made to reduce the risk. Risk reduction measures should be implemented urgently.

- Very High: Risk is unacceptable. Substantial improvements in risk controls are necessary, so that the risk is reduced to an acceptable level.

For the assessment of the H\&S risk associated with CPFs this five-band categorisation was adapted. Applying this categorisation to Table 2, as no exposure results in no risk and similarly the absence of potential to cause harm also results in no risk (Duffus and Worth, 2001; HSE, 2001), the ' 0 ' risk values in Table 3 were assigned a 'No risk' category. Risk score ' 4 ' being the highest, was thus assigned a 'Very high risk' category, and risk score ' 2 ' being the mid score was assigned a 'Medium risk' category. Risk score ' 1 ' being the next risk score below risk score ' 2 ' was assigned a 'Low risk' category and finally risk score ' 3 ' being the next risk value above risk score '2' was assigned a 'High risk' category. Assigning the qualitative risk categories to the numeric scores, results in an interpretable risk combination matrix given by Table 3 . Following the systematic definition of the risk categories, the H\&S risk associated with CPFs was assessed by combining the mean scores of degree of potential of CPFs to influence accident occurrence (in Table 1) and the binary scores for exposure. The eventual risk assessment is presented next.

Table 3: Risk combination matrix with defined risk categories

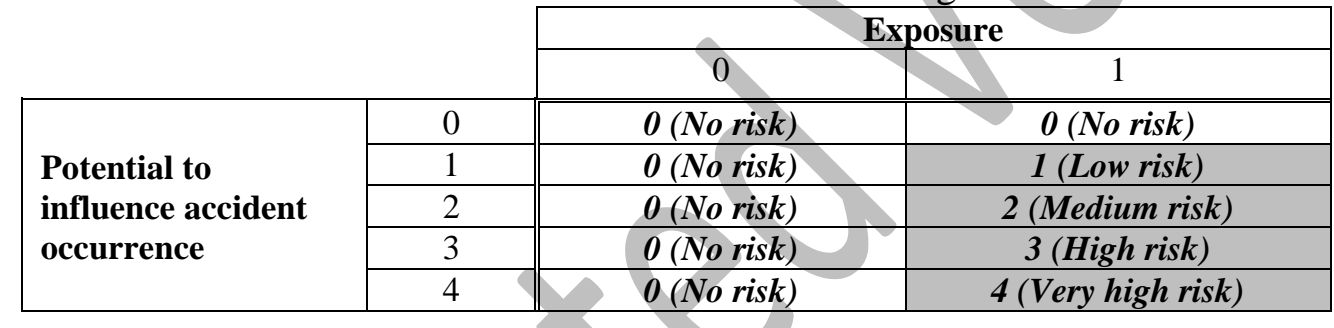

\section{Results \& Discussion: H\&S Risk Associated with CPFs}

The outcome of the risk combination is given by Table 4. From the assessment, where a CPF applies to a project, demolition has the highest degree of risk (i.e. risk score 3.17) and preassembly construction has the lowest degree of risk (i.e. risk score 1.51). To assist with better interpretation of the numeric risk scores, they are approximated to the nearest risk score to give an overall risk category. From Table 4, the degree of H\&S risk associated with a CPF where it applies on a project can be generally considered as either being high risk or medium risk. Amongst the 22 CPFs, 9 are high risk features implying they are associated with a high likelihood of accident occurrence. The remaining $13 \mathrm{CPFs}$ are medium risk features implying they are associated with medium likelihood of accident occurrence. The overall risk assessment is consistent with some of the few qualitative comparative risk evaluations in literature such as new work being considered as having less risk than refurbishment (Anumba et al., 2006). However, contrary to pre-assembly construction being considered as having less degree of H\&S risk than traditional method of construction (see McKay et al., 2002) the assessment given by Table 5 indicates that pre-assembly and traditional construction are similarly medium-risk CPFs. In terms of acceptability of risk, referring to the guidance by the BSI (2008), none of the CPFs is associated with acceptable risk indicating that whichever CPFs apply to a project, measures need to be undertaken to mitigate their associated risk, albeit the extent of the measures should depend on the degree of risk. Whereas for medium risk CPFs consideration should be given as to whether risk can be lowered further, for high risk CPFs substantial measures are required to be implemented. 
Table 4: Risk combination matrix for evaluation of the H\&S risk associated with CPFs

\begin{tabular}{|c|c|c|c|c|c|}
\hline \multicolumn{2}{|c|}{ Potential to influence accident occurrence } & \multicolumn{2}{|c|}{ Exposure } & \multicolumn{2}{|c|}{$\begin{array}{l}\text { H\&S Risk associated } \\
\text { with CPF where CPF } \\
\text { applies to a Project }\end{array}$} \\
\hline & & 0 & & High & \\
\hline Construction Project Features & Mean score & $\begin{array}{c}\text { (CPF does not } \\
\text { apply to a project) }\end{array}$ & $\begin{array}{l}\text { (CPF applies } \\
\text { to a project) }\end{array}$ & $\begin{array}{c}\text { Risk } \\
(3)\end{array}$ & $\begin{array}{c}\text { Medium Risk } \\
\text { (2) }\end{array}$ \\
\hline Demolition & 3.17 & 0 & 3.17 & $\checkmark$ & \\
\hline Underground construction & 2.84 & 0 & 2.84 & $\checkmark$ & \\
\hline Tight project duration & 2.84 & 0 & 2.84 & $\checkmark$ & \\
\hline High-level construction & 2.76 & 0 & 2.76 & $\checkmark$ & \\
\hline Multi-layer subcontracting & 2.7 & 0 & 2.7 & $\checkmark$ & \\
\hline $\begin{array}{l}\text { Complex design (i.e. design with } \\
\text { intricate aesthetic qualities) }\end{array}$ & 2.61 & 0 & 2.61 & $\checkmark$ & \\
\hline $\begin{array}{l}\text { Restricted site (i.e. where } \\
\text { footprint of facility covers most of } \\
\text { the site area) }\end{array}$ & 2.61 & 0 & & $\checkmark$ & \\
\hline $\begin{array}{l}\text { Restricted site locality e.g. city } \\
\text { centre location }\end{array}$ & 2.57 & 0 & & $\checkmark$ & \\
\hline Refurbishment & 2.52 & 0 & 2.52 & $\checkmark$ & \\
\hline Traditional on-site construction & 2.22 & 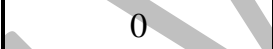 & 2.22 & & $\checkmark$ \\
\hline New work & 1.99 & 0 & 1.99 & & $\checkmark$ \\
\hline Management contracting & 1.95 & 0 & 1.95 & & $\checkmark$ \\
\hline Design and build procurement & 1.83 & 0 & 1.83 & & $\checkmark$ \\
\hline $\begin{array}{l}\text { Traditional method of } \\
\text { procurement }\end{array}$ & 1.81 & 0 & 1.81 & & $\checkmark$ \\
\hline Unrestricted site locality & 1.8 & 0 & 1.8 & & $\checkmark$ \\
\hline Unrestricted site & 1.79 & 0 & 1.79 & & $\checkmark$ \\
\hline Partnering procurement & 1.77 & 0 & 1.77 & & $\checkmark$ \\
\hline Low-level construction & 1.71 & 0 & 1.71 & & $\checkmark$ \\
\hline Adequate project duration & 1.66 & 0 & 1.66 & & $\checkmark$ \\
\hline Single-layer subcontracting & 1.63 & 0 & 1.63 & & $\checkmark$ \\
\hline Simple design & 1.55 & 0 & 1.55 & & $\checkmark$ \\
\hline Pre-assembly construction & 1.51 & 0 & 1.55 & & $\checkmark$ \\
\hline
\end{tabular}

\section{Development \& Verification of a Simple Pre-construction Phase Project H\&S Risk Profiling Tool \\ Tool development}

The features of projects can vary from project to project, and as such the features of a project "A" (e.g. refurbishment, high-level construction, tight duration, etc.) can differ from another project "B" (e.g. new build, low-level construction, complex design). It is thus desirable to have a simple tool that would enable project participants (at pre-construction stage) to select the features that apply/would apply to a project and view an overall H\&S risk profile for the project (based on the selected/applicable features). In view of this a simple computer-based tool using Microsoft Excel was developed to represent the risk information given by Table 5. Microsoft Excel, amongst its several functions for executing tasks, has a function called the "IF function" (Bluttman and Aitken, 2010). The IF function returns a value if a condition is true and another value if that condition is false (Bluttman and Aitken, 2010). This function can be very useful 
where among several possible scenarios a user wishes to display only the specific information relevant to a particular scenario. As different CPFs may apply to any single project, this function in Microsoft Excel can be used to create a series of instructions which retrieve and display only the $H \& S$ risk profile related to a selection of CPFs which apply to a project. This function in Microsoft Excel was thus used extensively in creating a simple pre-construction phase project risk profiling tool. Aside displaying the $H \& S$ risk profile of a project, the tool included suggestions for mitigating the risk associated with the CPFs. The suggestions are based on the hierarchy of risk control (BSI, 2008; and Hughes and Ferrett, 2008) and the effect of two factors that have been shown to affect the potential of a CPF to influence accident occurrence: (1) the potential of proximate accident cause(s) which are related to the CPF to influence accident occurrence; and (2) the degree of prevalence of the proximate accident cause(s) within a CPF (Manu et al, 2014). For example high-level construction is related to the proximate accident cause, "working at height" (see Chapter - A Model of How Features of Construction Projects Influence the Occurrence of Accidents on Projects). From Manu et al., (2014) the potential for high-level construction to influence accident occurrence is therefore related to: the potential for "working at height" to influence accident occurrence (i.e. the potential for working at height to cause harm); and the degree to which "working at height" is prevalent within high-level construction. To mitigate the level of H\&S risk associated with high-level construction, there is therefore the need to either, (1) mitigate the potential of "working at height" to cause harm by making it safe for operatives to work at height (e.g. using fall protection); and/or (2) mitigate the prevalence of "working at height" (e.g. reducing the need for operatives to work at height by designing out work at height). The Microsoft Excel tool has been nicknamed, "CRiMT". Figure 1 is a screenshot illustration of "CRiMT"

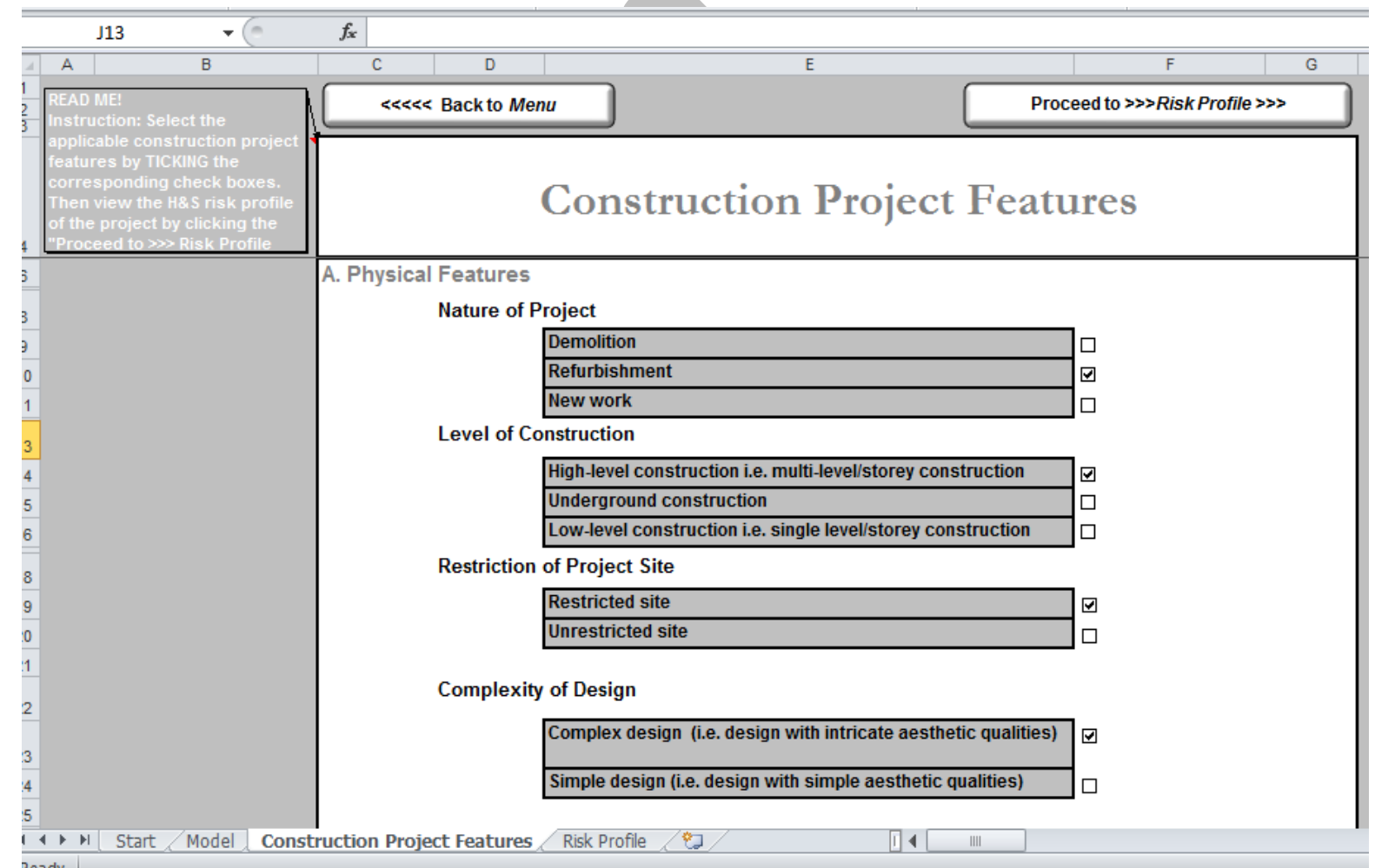

Figure 1: Screenshot illustration of "CRiMT"

\section{Tool verification}

To enable verification of the risk information in Table 4 and the industrial relevance of the tool to pre-construction $\mathrm{H} \& \mathrm{~S}$ planning, the tool was tested by experienced construction professionals 
in construction management related roles. The professionals were asked to trial the tool by selecting the features of a recently completed project they have worked on and then proceeding to view the H\&S risk profile displayed by the tool. They were then asked to respond to three main questions. The first question was about the similarity between the displayed H\&S risk profile and the actual $H \& S$ risk experienced on the project. The remaining two questions which explored the relevance of the tool to pre-construction $H \& S$ planning were only applicable to those respondents whose organisation's operations involve early (e.g. concept/design stage) H\&S planning e.g. housing development, design and build, etc. The demographic information of the professionals $(n=13)$ is provided in Part A of Table 5 below.

Table 5: Tool verification feedback

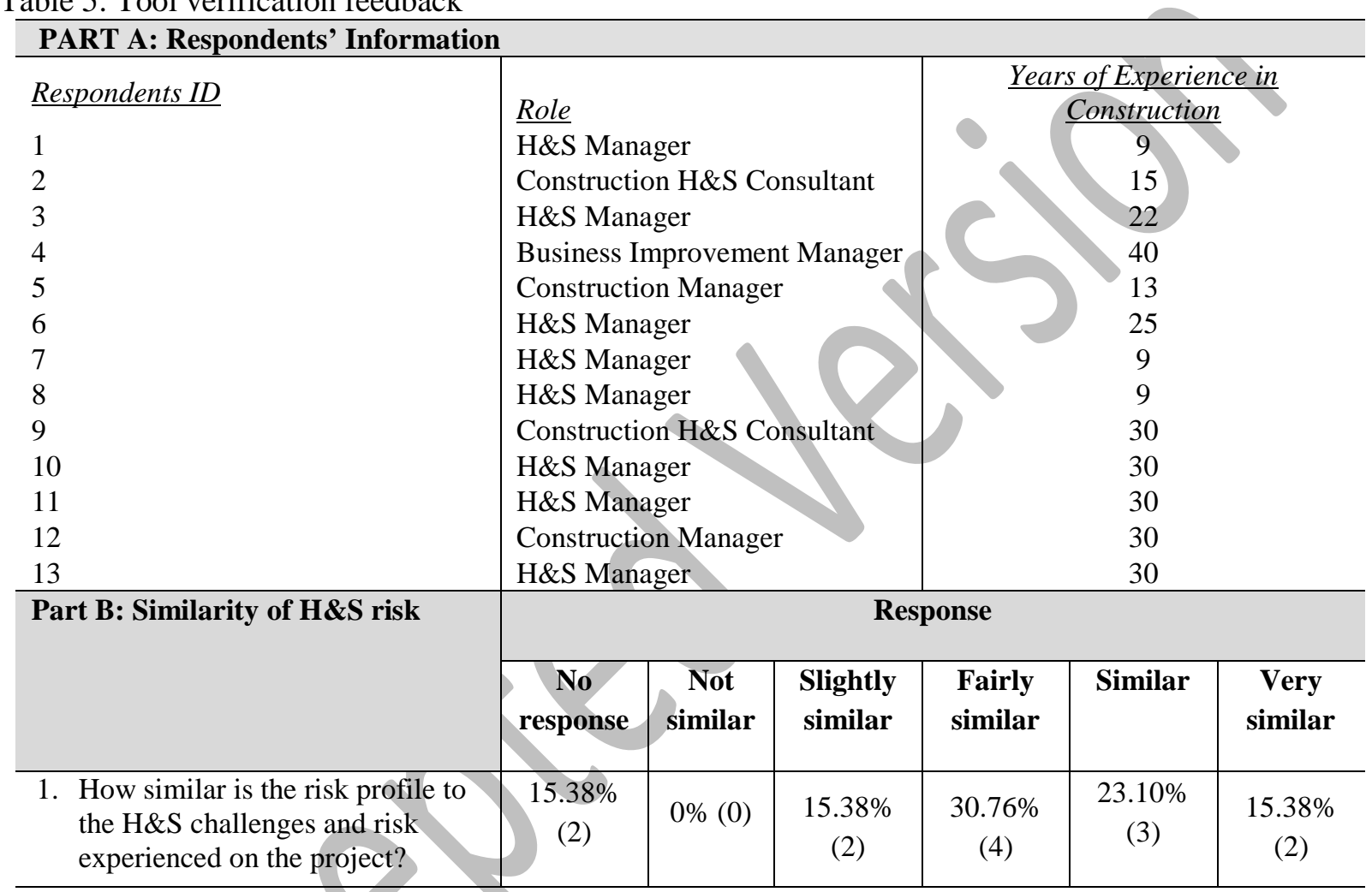

Note: Outside bracket represents number of respondents.

\begin{tabular}{|c|c|c|c|c|c|c|}
\hline \multirow{2}{*}{$\begin{array}{l}\text { Part C: Usefulness of tool to pre- } \\
\text { construction H\&S planning }\end{array}$} & \multicolumn{6}{|c|}{ Response } \\
\hline & $\begin{array}{c}\text { No } \\
\text { response }\end{array}$ & $\begin{array}{c}\text { Not } \\
\text { useful }\end{array}$ & $\begin{array}{c}\text { Slightly } \\
\text { useful }\end{array}$ & $\begin{array}{l}\text { Fairly } \\
\text { useful }\end{array}$ & Useful & $\begin{array}{c}\text { Very } \\
\text { Useful }\end{array}$ \\
\hline $\begin{array}{l}\text { 2. At the concept/design stage of a } \\
\text { new development how useful } \\
\text { could risk information such as } \\
\text { that provided by this tool be in } \\
\text { terms of informing/influencing } \\
\text { decisions that determine CPFs? }\end{array}$ & $\begin{array}{l}18.18 \% \\
(2)\end{array}$ & $0 \%(0)$ & $\begin{array}{c}9.09 \% \\
(1)\end{array}$ & $\begin{array}{c}36.36 \% \\
(4)\end{array}$ & $\begin{array}{l}18.18 \% \\
(2)\end{array}$ & $\begin{array}{l}18.18 \% \\
(2)\end{array}$ \\
\hline $\begin{array}{l}\text { 3. At the concept/design stage of a } \\
\text { new development how useful } \\
\text { could risk information such as } \\
\text { that provided by this tool be in } \\
\text { terms of informing/influencing } \\
\text { the planning of design or project }\end{array}$ & $0 \%(0)$ & $0 \%(0)$ & $\begin{array}{l}9.09 \% \\
(1)\end{array}$ & $\begin{array}{l}45.45 \% \\
(5)\end{array}$ & $\begin{array}{l}27.27 \% \\
\text { (3) }\end{array}$ & $\begin{array}{l}18.18 \% \\
\text { (2) }\end{array}$ \\
\hline
\end{tabular}


management solutions to control $\mathrm{H} \& \mathrm{~S}$ risk posed by CPFs?

Note: Total number of applicable respondents $=11$. Outside bracket represents number of respondents. Applicable respondents are those whose organisation's operations are likely to involve early (e.g. concept/design stage) H\&S planning e.g. housing development.

The minimum and mean number of years of experience of the respondents in construction is 9 years and 22.53 years respectively. Collectively, this indicates a respectable amount of experience in the management of construction and H\&S (see Hallowell and Gambetese, 2010) and therefore their feedback can be deemed credible. In terms of how the risk profile given by the toolkit compares with the H\&S challenges and risk experienced on the respondents' projects, as shown by Part B of Table 5, the responses range from slightly similar to very similar with a majority of the respondents (i.e. 9 representing 69.24\%) indicating at least a fair similarity. This means that the risk information given by the tool reasonably reflects the actual H\&S risk situations induced by the CPFs on the respondents' projects. The responses (given in Part C of Table 5) indicate that for 11 of the 13 respondents the nature of their organisations' operation involves pre-construction decision-making which, among others, determines CPFs and also planning design or project management solutions to control H\&S risk posed by CPFs. These respondents include two H\&S consultants whose role involves advising on such matters. As can be seen from Table 5, a majority of the respondents (i.e. 8 out of the 11 , representing $72.72 \%$ ) indicated that the information given by the toolkit is at least fairly useful for informing/influencing decisions that determine CPFs. Again a majority of the respondents (i.e. 10 out of the 11, representing $90.91 \%$ ) indicate that the information given by the tool is at least fairly useful for informing/influencing the planning of design or project management solutions to control H\&S risk posed by CPFs. Overall, these indicate that the risk information given by the tool is of practical relevance to managing the $\mathrm{H} \& \mathrm{~S}$ risk posed by CPFs during the preconstruction stage of project delivery.

\section{Implications}

In the light of the overall risk assessment, high risk CPFs (e.g. tight project schedules and intricate designs) should certainly not be taken lightly. For instance clients ought to allow sufficient time and resources for projects and designers ought to produce designs that would be safe for contractors to build and maintain. In the UK this is required under the CDM regulations. Adhering to such requirements should not be taken as being trivial or as a mere tick in the box exercise as there is a great likelihood of accidents occurring on projects where these features and similar high risk features apply. As CPFs emanate from the pre-construction stage of project procurement through decisions by the client, design team and project management team, these project participants have an enormous opportunity to mitigate the H\&S risk associated with projects by virtue of their characteristics. In making decisions which determine CPFs, the decision makers could select medium risk $\mathrm{CPFs}$ over high risk $\mathrm{CPFs}$ as there is relatively less likelihood of accident occurrence associated with medium risk CPFs. As the selection of a high risk CPF may be inevitable in some situations due to possible project constraints such as client requirements (Suraji et al., 2001), pre-construction project participants would have to implement risk mitigation measures. In doing so, greater priority ought to be given to high risk CPFs and as such substantial efforts (i.e. resources) will have to be allocated towards mitigating the risk associated with high risk CPFs. With medium risk CPFs, as there is still some likelihood of accident occurrence where such CPFs apply, they cannot be totally disregarded. As recommended by the BSI (2008), further consideration ought to be given as to whether the risk can be reduced further while taking into account the cost of any measures. 
In all, the risk assessment accords each CPF its degree of $\mathrm{H} \& \mathrm{~S}$ risk which allows for comparison amongst all the CPFs. The risk assessment offers an important insight which should assist project participants in ascertaining the H\&S risk profile of projects at the pre-construction stage. The risk assessment could also inform pre-construction decision-making regarding CPFs as well as the prioritisation of risk control measures. In this light, CRiMT could be a useful resource especially to project participants who may have limited experience in managing the H\&S risk posed by certain features of construction projects.

\section{Conclusions}

Ascertaining the H\&S risk profile of a construction project can be difficult especially at the preconstruction stage of a project due to the often limited information available at that stage. It may also be difficult for some project participants if they have limited experience of delivering some kind of projects. However, based on some attributes of projects which emanate from preconstruction decisions and also influence accident occurrence, it can be possible to gauge the $\mathrm{H} \& \mathrm{~S}$ risk profile of a project at the preconstruction stage. In this chapter, the degree of $\mathrm{H} \& \mathrm{~S}$ risks associated with construction project features (CPFs) (e.g. nature of project, method of construction, project duration, level of construction, subcontracting, design complexity, site restriction and procurement system) have been evaluated using a semi-quantitative risk evaluation technique and an adapted mathematical H\&S risk expression. Quantitative inputs for the expression were partly provided by the results of a questionnaire survey. The risk evaluation shows that the CPFs are generally associated with high risk or medium risk, implying that they are generally associated with a high likelihood of accident occurrence or a medium likelihood of accident occurrence. Whereas with medium risk CPFs some risk control measures will suffice in mitigating risk, with high risk CPFs substantial measures are required. These findings have implications for pre-construction decision making regarding CPFs and also the prioritisation of risk control measures. CRiMT, a simple $H \& S$ risk assessment tool developed from the evaluation, could be a useful resource to pre-construction project participants in ascertaining the $\mathrm{H} \& \mathrm{~S}$ risk profile of a construction project based on its applicable/relevant features in order to guide the introduction of appropriate $H \& S$ risk control measures. Construction accident causation being a complex phenomenon can however involve inter-causal relationships (see Chapter - A Model of How Features of Construction Projects Influence the Occurrence of Accidents on Projects) amongst causal factors which could affect the H\&S risk associated with a CPF. As a limitation of CRiMT, the potential effect of inter-causal relationships on the H\&S risk associated with a CPF is not taken into account. Also beyond the CPFs that were investigated in this chapter, there may be other features of project (determined by pre-construction decisions) that also have an accident causal role. The CPFs included in CRiMT are therefore not exhaustive. CRiMT should therefore not be viewed as a static tool, but rather as a dynamic tool for which subsequent versions incorporating new insights can be developed.

\section{References}

Aven, T. (2008), "A semi-quantitative approach to risk analysis, as an alternative to QRAs", Reliability Engineering and Systems Safety, Vol. 93, No. 3, pp.768-775.

Ankrah, N.A. (2007), "An investigation into the impact of culture on construction project performance", $\mathrm{PhD}$ Thesis, University of Wolverhampton.

Anumba, C., Egbu, C. and Kashyap, M. (2006), “Avoiding structural collapses in refurbishment - A decision support system”, Suffolk, HSE Books.

Anumba, C., Egbu, C. and Kashyap, M. (2006), "Avoiding structural collapses in refurbishment - A decision support system”, Suffolk, HSE Books.

Bluttman, K. and Aitken, P.G. (2010), "Excel formulas and functions for dummies", Hoboken, New Jersey, Wiley Publishing. 
Bomel Limited, Glasgow Caledonian University and The Institute for Employment Research (2006), "An analysis of the significant causes of fatal and major injuries in construction in Scotland- Factors influencing Scottish construction accidents-FISCA", Research Report 443, Suffolk, HSE Books.

Brabazon, P., Tipping, A. and Jones, J. (2000), "Construction health and safety for the new Millennium", Suffolk, HSE Books.

Brace, C., Gibb, A., Pendlebury, M. and Bust, P. (2009), "Phase 2 Report: Health and safety in the construction industry: Underlying causes of construction fatal accidents -External research", Norwich, Her Majesty's Stationery Office.

British Standard Institute (2008), "Guide to achieving effective occupational health and safety performance”, BS 18004:2008, London, British Standard Institute.

Canadian Centre for Occupational Health and Safety (2008), "Risk versus hazards", Canadian Centre for Occupational Health and Safety

Chicken, J.C. and Posner, T. (1998), "The philosophy of risk", Thomas Telford, London.

Chua, D. K. H. and Goh, Y. M. (2005), "Poisson model of construction incident occurrence", Journal of Construction Engineering and Management, Vol. 131, No. 6, pp.715-722.

Cooke, T. and Lingard, H. (2011), "A retrospective analysis of work-related deaths in the Australian construction industry", In: Egbu, C. and Lou, E. C. W. (eds.) Proceeding of 27th Annual ARCOM Conference, 5-7 September 2011. Bristol, UK. Association of Researchers in Construction Management, pp.279-288.

Department of Occupational Health and Safety (2015), "Occupational accidents statistics by Sector until December 2015", Department of Occupational Health and Safety. Available online at http://www.dosh.gov.my/index.php/en/archive-statistics/2015/1713occupational-accidents-statistics-by-sector-until-december-2015 . Accessed 12/07/2016

Duffus, J. and Worth, H. (2001), "The science of chemical safety essential toxicology- An educational resource", International Union of Pure and Applied chemistry.

Egbu, C.O. (1999), "Skills, knowledge and competencies for managing construction refurbishment works", Construction Management and Economics, Vol. 17, No. 1, pp.2943.

Hallowell, M. R. and Gambatese, J. A. (2010), "Qualitative research: application of the Delphi method to CEM research", Journal of Construction Engineering and Management, Vol. 136, No. 1, pp. 99-107.

Hide, S. (2003), "Exploring accident causation in the construction industry", $\mathrm{PhD}$ thesis, Department of Building and Civil Engineering, Loughborough University.

Hide, S., Atkinson, S., Pavitt, T., Haslam, R., Gibb, A., Gyi, D, Duff, R. and Suraji, A. (2003), "Causal factors in construction accidents", Suffolk, HSE Books.

Horbury, C. and Hope, C. (1999), "The impact of procurement and contracting practices on health and safety - A review of literature", Report RAS/99/02, Buxton, HSL.

HSE (2000), "Management of Health and Safety at Work Regulations 1999 Approved Code of Practice \& Guidance”, 2nd ed., Suffolk, HSE Books.

HSE (2001), "Reducing risks: Protecting people - HSE's decision making process", Suffolk, HSE Books.

HSE (2006), "Five steps to risk assessment", Suffolk, HSE Books.

HSE (2009), "Construction intelligence report: Analysis of construction injury and ill-health intelligence", Health and Safety Executive, Available online at http://s3.amazonaws.com/zanran_storage/www.hse.gov.uk/ContentPages/25543732.pdf (Accessed 1st January 2011) 
HSE (2015a), "Historical picture - HISTINJ-Reported injuries in Great Britain by main industry and severity of injury, 1974 to latest year", HSE. Available online at http://www.hse.gov.uk/Statistics/tables/index.htm [Access 12/07/2016]

HSE (2015b), "Managing health and safety in construction - CDM 2015 Guidance L153", HSE. Hughes, P. and Ferrett, E. (2008), "Introduction to health and safety in construction", 3rd edn., Oxford, Elsevier Ltd.

ILO (2005), "Global estimates of fatal work related diseases and occupational accidents", World Bank Regions", Geneva, ILO.

James, L. R., Demaree, R. G. and Wolf, G. (1984), "Estimating within-group interrater reliability with and without response bias", Journal of Applied Psychology, Vol. 69, No. 1, pp.85-98.

Jannadi, O.A. and Almishari, S. (2003), "Risk assessment in construction", Journal of Construction Engineering and Management, Vol. 129, No. 5, pp.492-500.

Kariuki, S. and Löwe, K. (2007), "Integrating human factors into process hazard analysis", Reliability Engineering and System Safety, Vol. 92, No. 12, pp.1764-1773.

Knab, L.I. (1978), "Numerical aid to reduce construction injury losses", Journal of the Construction Division, Vol. 104, No. 4, pp.437-445.

Manu, P., Ankrah, N., Proverbs, D. and Suresh, S. (2012), "Investigating the multi-causal and complex nature of the accident causal influence of construction project features", Accident Analysis and Prevention, Vol 48, pp. 126-133.

Manu, P., Ankrah, N., Proverbs, D. and Suresh, S. (2013), "Mitigating the health and safety influence of subcontracting in construction: The approach of main contractors" International Journal of Project Management, Vol. 31, No. 7, pp. 1017 - 1026.

Manu, P., Ankrah, N., Proverbs, D. and Suresh, S. (2014), "The health and safety impact of construction project features", Engineering, Construction and Architectural Management, Vol. 21, No. 1, pp. 65 - 93.

Mayhew, C. and Quinlan, M. (1997), "Subcontracting and occupational health and safety in the residential building industry", Industrial Relations Journal, Vol. 28, No. 3, pp.192-205.

McKay, L.J., Gibb, A.G.F., Haslam, R. and Pendlebury, M. (2002), "Implications for the effect of standardization and pre-assembly on health, safety and accident causality- preliminary results", in 18th Annual ARCOM Conference, 2-4 September 2002, University of Northumbria. Association of Researchers in Construction Management.

Ministry of Manpower (2015), "A healthy workforce in a safe workplace - Annual Report 2015", Ministry of Manpower. Available online at http://www.mom.gov.sg/ebook/oshdar2015/pdf/OSHD_AR2016_LoRes.pdf. Accessed 12/07/2016

Perttula, P., Merjama, J., Kiurula, M. and Laitinen, H. (2003), "Accidents in materials handling at construction sites", Construction Management and Economics, Vol. 21, No. 7, pp.729736.

Pinto, A., Nunes, I.L. and Ribeiro, R.A. (2011), "Occupational risk assessment in construction industry-Overview and reflection", Safety Science, Vol. 49, No. 5, pp. 616-624.

Risk \& Policy Analyst Ltd. (1999), "Risk ranking for small and medium enterprises", Suffolk, HSE Books.

Sachs, T. and Tiong, R.L.K. (2009), "Quantifying qualitative information on risks: Development of the QQIR method", Journal of Construction Engineering and Management, Vol. 135, No. 1, pp.56-71.

Sacks, R., Rozenfeld, O. and Rosenfeld, Y. (2009), "Spatial and temporal exposure to safety hazards in construction", Journal of Construction Engineering and Management, Vol. 135, No. 8, pp.726-736.

Smith, N.J., Merna, T. and Jobling, P. (2006), "Managing risk in construction projects", 2nd ed., Oxford, Blackwell Publishing. 
Strategic Forum for Construction (2002), "Accelerating change- A report by the Strategic Forum for Construction Chaired by Sir John Egan", Rethinking Construction, London.

Suraji, A. (2001), "Development and validation of a theory of construction accident causation", PhD Thesis, UMIST.

WHO and FAO (2009), "Risk characterization of microbiological hazards in foodMicrobiological risk assessment series 17", WHO and FAO.

Wright, M., Bendig, M., Pavitt, T. and Gibb, A. (2003), "The case for CDM: better safer design-a pilot study", Suffolk, HSE Books. 